Fedea Policy Papers - 2016/23

Tuition Fees and Student Effort at University

P. Beneito

(University of Valencia and ERI-CES)

J.E. Boscá

(University of Valencia and Fedea)

J. Ferri

(University of Valencia and Fedea) 


\section{RESUMEN (NON TECHNICAL SUMMARY)}

En España, el Gobierno aprobó en el año 2012 un real decreto-ley para racionalizar el gasto público en el ámbito educativo que, entre otras medidas, dejaba un amplio margen para que las universidades incrementaran las tasas universitarias. Muchas universidades así lo hicieron, aplicando además incrementos mayores en función del número de veces que el estudiante se matricula antes de aprobar la asignatura.

En este trabajo nos fijamos en los efectos potenciales del incremento observado en las tasas para estimular el esfuerzo académico de los estudiantes. Utilizando datos anónimos de los registros administrativos de la población de estudiantes matriculada en la Universidad de Valencia en los grados de economía, ADE y medicina desde 2010 hasta 2014, investigamos con técnicas econométricas si el aumento escalonado de las tasas de matrícula ha tenido algún efecto sobre: (1) el número de veces que el estudiante se matricula para superar el módulo, (2) la probabilidad de aprobar la asignatura a la primera y (3) las calificaciones medias.

Nuestra estrategia de identificación del efecto del aumento de las tasas se basa en una estimación flexible de diferencia-en-diferencias, donde explotamos el hecho de que existen grupos de estudiantes sujetos a regímenes diferentes en el pago de tasas por matrícula. En un mundo de laboratorio, la identificación del efecto causal de la medida de política analizada implicaría la observación de como el estudiante habría actuado con la medida y en ausencia de la misma, es decir, la observación de un contrafactual.

Como el contrafactual no es observable, la aproximación utilizada compara el comportamiento tras la subida de las tasas de aquéllos estudiantes afectados por la medida (o grupo de individuos tratados) con aquéllos no afectados por la misma (o grupo de control). En nuestro caso, hemos utilizado como grupo de control los estudiantes con exención completa de tasas de matrícula, no sujeta al rendimiento académico (es decir, no becados). Estos estudiantes pertenecen a alguna de las siguientes tres categorías: familias numerosas, estudiantes con una incapacidad igual o superior al 33 por cien, y víctimas del terrorismo.

De nuestro trabajo se desprende que la subida observada de las tasas universitarias ha tenido los siguientes efectos sobre el rendimiento académico, que apuntan a un aumento en el esfuerzo de los estudiantes:

o Ha reducido el número medio de veces que un estudiante se matricula antes de aprobar.

o Ha aumentado la probabilidad de aprobar en primera matrícula.

o Ha mejorado las calificaciones.

Los resultados anteriores difieren en tamaño dependiendo de la habilidad del estudiante (medida a partir de la nota de entrada en la universidad), el grado (economía-ADE o medicina) y el tiempo transcurrido desde la medida. En particular: 
o El efecto de la medida sobre el rendimiento académico es mayor para los estudiantes más débiles que para los mejores estudiantes, mayor para economía-ADE que para medicina y ha aumentado entre los años 2012 y 2014.

o A modo de ejemplo, los estudiantes más débiles en economía y ADE han aumentado la probabilidad de aprobar en primera matrícula en 10 puntos porcentuales, y han reducido a la mitad el tiempo extra requerido para aprobar un módulo.

o La principal reacción de los estudiantes más aventajados al aumento del coste de la matrícula se observa en un aumento de las calificaciones (de 0.8 puntos sobre 10 en economía y ADE y de 0.6 puntos en Medicina).

La mayoría de las universidades han utilizado el real decreto para subir las tasas, tanto para los estudiantes que se matriculan por primera vez de un módulo como para los repetidores. Sin embargo, la diferencia de la subida de tasas entre la primera y posteriores matriculas ha sido muy diferente dependiendo de la comunidad autónoma en la que la universidad se encuentre. En efecto, algunas universidades decidieron subir poco las tasas en primera matrícula y aumentarlas mucho para los estudiantes repetidores, mientras que otras eligieron ya una fuerte subida desde la primera matrícula.

En el trabajo también planteamos un modelo teórico que es capaz de explicar nuestros resultados empíricos. Este modelo se utiliza también para hacer un experimento, simulando el esfuerzo de los estudiantes si se hubiera cambiado el esquema de subida de tasas en dos direcciones distintas. En un primer caso se mantiene constante el coste de la matrícula para los nuevos matriculados, elevándolo sólo para los repetidores. En el segundo, el coste de la matrícula aumenta por igual con independencia del número de veces que el estudiante se matricule. En ambos casos generamos una subida de las tasas que aumenta la recaudación en la misma medida que si se hubiera utilizado el esquema empleado en la Universidad de Valencia. En otras palabras, obligamos a los dos esquemas opuestos de tasas a generar los mismos ingresos para la universidad.

Nuestros resultados sugieren que el diseño basado en mantener las tasas de entrada y aumentar la penalización en el coste de la matrícula de los repetidores provoca el mayor efecto positivo sobre el rendimiento académico, a costa de un mayor esfuerzo de los estudiantes. Dado que este diseño es también probablemente el que menos distorsiones genera sobre la decisión de entrar en la universidad, creemos que es el más adecuado para satisfacer simultáneamente el objetivo de recaudación y de ganancia de eficiencia en la utilización del servicio público de la educación universitaria. 


\title{
Tuition Fees and Student Effort at University
}

\author{
P. Beneito ${ }^{a, b}$, J.E. Boscáa ${ }^{a, c}$ and J. Ferri ${ }^{a, c}$
}

\begin{abstract}
This paper presents theoretical and empirical evidence that an increase in tuition fees may boost university students' academic effort. We examine the tuition fee rise introduced in 2012 by Spanish universities, where students register and pay for their chosen modules and fees increase each time students retake a module until they pass it. Data refer to students of economics, business and medicine at the University of Valencia during 2010-2014. The fact that some students pay fees in full while others are exempt from payment provides an identifying source of variation that we exploit using a flexible difference-in-differences methodology.
\end{abstract}

Keywords: tuition fees, academic effort, university degrees, difference-indifferences.

JEL classification: I22, I23, C23.

Corresponding author: francisco.ferri@uv.es

${ }^{a}$ University of Valencia; ${ }^{b}$ ERI-CES; ${ }^{c}$ Fedea.

We thank the administration of the University of Valencia for providing the data and, especially, Elena Barea for kindly answering all our questions. We acknowledge comments by Javier Andrés, Giorgio Brunello, Rafael Doménech, Antonio Cabrales and Maite Martínez-Granado. We also thank Francisco Alcalá, Vicente Cuñat, Francisco Pérez and other participants at Workshop Anaeco 2016 for their suggestions. Pilar Beneito acknowledges financial support from the Spanish Ministerio de Economía y Competitividad (ECO2014-55745-R), Fundación-BBVA (Programa de Ayudas a Proyectos de Investigación en Socioeconomía, 2014) and from the Generalitat Valenciana (PROMETEOII/2014/054). José E. Boscá and Javier Ferri acknowledge financial support from Ministerio de Economía y Competitividad (ECO2014-53150-R), Prometeo (GVPROMETEO2016-097), Fundación Rafael del Pino and BBVA-Research. 


\section{Introduction}

The steady growth in university enrolments over the last decades, together with the adverse effects of the recent Great Recession, has led governments in several developed countries to approve significant cuts to higher education subsidies. The UK is perhaps one of the more salient examples in this regard, with higher education reforms involving the introduction of an almost three-fold increase in tuition fees in 2006/7 (as compared with fees first introduced in 1998/9) and again in 2012/13. Also in 2012, the Spanish government passed Law 14/2012, in a self-declared attempt to rationalise public expenditure by shifting a higher part of the costs of education onto the students. In the Spanish case, depending on the university and on the number of times the student has registered for the same module, tuition fees may be almost triple those charged before 2012 .

Despite the clear budgetary objective, the main argument for raising tuition fees is that students should bear a higher share of the costs of education since they are the direct beneficiaries. The work of Greenaway and Haynes (2003), for instance, advocates for a larger private contribution from students accompanied by increased availability of income-contingent loans. Standard economic theory, however, provides arguments to support public subsidies for higher education, given that it is an activity with clear positive externalities. When viewed in this light, high tuition fees become the subject of much discussion. ${ }^{1}$

In this paper, we investigate a much less widely discussed aspect of increases in higher education tuition fees. By exploiting the particular characteristics of enrolment and the 2012 tuition fee rise in Spanish public universities, we examine the potential effects of tuition fees on university students' academic effort. More specifically, we try to both theoretically explain and to empirically measure whether increased tuition fees encourage students to use the educational resources more efficiently. An affirmative answer to this question would be highly desirable from an educational policy point of view.

Our empirical analysis is based on data from the University of Valencia (UV henceforth), one of the largest public universities in Spain. The UV provided us with anonymised administrative records for the entire population of students in economics, business and medicine, enrolled from 2010 to 2014. Unlike other higher education systems around the world, students at UV and in the rest of the public universities in Spain do not pay a fixed amount per academic year. Spanish students register and pay tuition fees for their

\footnotetext{
${ }^{1} \mathrm{~A}$ recent study by Pérez, Pastor and Peraita (2015) estimates returns of around 2.6 euros on 1 euro of investment in education, in the form of taxes collected by the public sector from university graduates over their lifetimes. This study uses data from public universities in the Valencian region, in Spain.
} 
chosen modules, and the price of each modules is set according to the number of credits awarded. Law 14/2012 established a price increase that depends on the number of times the student has registered for a particular module before passing the corresponding exam. According to the law, university tuition fees should cover between 15 and 25 percent of the total cost of education for a first-time registration, between 30 and 40 percent for a second registration, between 65 and 75 percent if a student registers for a third time, and between 90 and 100 percent for fourth and subsequent registrations. ${ }^{2}$

This tuition fee structure is quite unique. Around the world, fees are generally paid per academic year rather than for modules or credits, and the prices are not contingent upon the academic achievements of students. However, Garibaldi et al. (2012) mention, in addition to Spain, a few exceptions: in Germany, for instance, between 1998 and 2005, some universities implemented a tuition structure whereby students pay more when they delay their graduation (see Heineck, et al., 2006); on the contrary, in some universities in Italy, students pay less when their enrolment in university extends beyond the standard length of the degree (fuori corso). A recent study by Sacristán (2014) reviews fee schemes in 38 European countries and reports that prices depend on students' performance in only four countries other than Spain: Austria, Slovakia, the Czech Republic and Poland. The payment scheme in those countries is, however, very different to the Spanish one. In Austria, Slovakia and the Czech Republic, students do not pay for their university studies unless they exceed the standard length by more than a year, whereas in Poland, students only pay if they do not pass a given number of credits per term or academic year.

Table 1 displays the tuition fee structure at UV in 2012/13 and compares it with prices in 2011/12. Within the limits established by Law 14/2012, the UV has set the fourth highest increase among public Spanish universities. Prices per credit in some disciplines such as medicine are higher than in social sciences, because they have a more experimental focus. The price hike is around 33 percent for first and second registration, while registering for a third or fourth time means more than doubling and tripling, respectively, the price per credit. With an average of 60 credits per academic year, these figures translate to average annual tuition fees after 2012 of around 1,000 euros in economics and business degrees (around 100 euros for each six-credit module) and around 1,500 euros in medicine (around 150 euros per module). The cost per module incurred by students who do not pass with their first registration rises to more than 180 euros in economics and business and to more than 250 in medicine. The corresponding prices for a fourth registration would amount to around 520 euros in economics and business and 730 euros in medicine.

\footnotetext{
${ }^{2}$ With each registration for a module, the student is allowed to take the exam twice.
} 
Table 1: Tuition fee per credit at the University of Valencia (euros)

\begin{tabular}{lcccc}
\hline \hline & $1^{\text {st }}$ Reg. & $2^{\text {nd }}$ Reg. & $3^{\text {rd }}$ Reg. & $4^{\text {th }}$ Reg. \\
\hline & & & & \\
Economics and Business 2011-12 & 13.07 & 22.87 & 28.75 & 28.75 \\
Economics and Business 2012-13 & 17.43 & 30.50 & 65.35 & 87.13 \\
(\% increase) & $(33.4 \%)$ & $(33.4 \%)$ & $(127.3 \%)$ & $(203.1 \%)$ \\
Medicine 2011-12 & 18.48 & 32.34 & 40.66 & 40.66 \\
Medicine 2012-13 & 24.64 & 43.12 & 92.40 & 123.20 \\
$(\%$ increase) & $(33.3 \%)$ & $(33.3 \%)$ & $(127.3 \%)$ & $(203.1 \%)$ \\
\hline
\end{tabular}

Has the change in this escalating tuition fee structure induced an increase in academic effort on the part of students? Has the number of registrations before students pass a subject fallen, or has the probability of passing an exam at the first sitting increased? How have academic grades changed? In our paper, we aim to provide some answers to these questions.

To that end, we first present a simple theoretical model where the student faces the leisure-consumption trade-off and decides on the level of effort to dedicate to their university studies. In our model, we address the question of how the student responds to increased tuition fees in terms of effort dedicated to passing their modules the first time around. Passing exams at the first attempt is equivalent to early completion of the degree, and we assume in our model that the labour market values this result. The model's results suggest that students will up their level of effort at university in response to the observed tuition fee rise. The model also shows that this response may be heterogeneous, with average students (those with low-to-medium academic ability) registering a greater reaction than their higher-achieving peers.

Our empirical strategy to identify the causal effect of the fee rise is based on a flexible difference-in-differences approach (DID henceforth), where we exploit the fact that there are different tuition regimes for different groups of students at UV. Along with students who pay 100 percent of their fees (we call these 'regular registration' students) there is a group of students who are fully exempt from paying fees, which serves as control group in the analysis. The assignment of students to total fee exemption is entirely exogenous: students belonging to a particular category of large families (those with 5 or more siblings), students with an officially recognised degree of disability equal to or greater than 33 percent, and victims of terrorism (this last category fortunately provides very few observations). We track the behaviour of regular registration students as compared to the behaviour of totally exempt students (or control group) over the period 2010-2014, and try to capture whether their comparative academic performance exhibits a change 
after the 2012 fee rise. In our estimations we seek to exploit the within-student and within-module time variation in the data to identify the effect of interest, while ruling out unobserved heterogeneity across students and modules. To this end, we apply the two high-dimensional fixed effects regression method proposed by Guimaraes and Portugal (2010) to our DID equations.

To anticipate our results, we find positive effects of the fee rise on UV students' level of effort, reflected in a lower number of registrations required to pass a module and a higher probability of passing with the first registration. The results are more visible in the case of average-ability students, and also in economics and business than in medicine. Positive effects on grades are also evident, although in this case top students show larger estimated responses. We also provide evidence that our results are not driven by changes in the sample composition stemming from selection of students either through enrolment or dropouts.

The rest of the paper is organised as follows. Next, in Section 2 we review the related literature to place our particular contribution in context. In Section 3, we present a theoretical model that illustrates the likely students' response to the fee rise. Further details on the institutional framework and our particular data set are presented in Section 4. Section 5 describes the empirical strategy, presents the main econometric results and provides evidence of robustness to enrolment and dropouts. In Section 6, we discuss some policy implications of our findings and, finally, we outline our conclusions in Section 7.

\section{Related literature and contribution}

There is scant literature on the direct effects of tuition fees on students' academic effort. Nearly everything that has been said on this matter comes from the abundant analysis linking tuition fees and financial aid with enrolment and dropout rates. Some recent references from this strand of the literature include the work of Hübner (2012) or Sá (2014), analysing the effect of tuition fees on enrolment in Germany and the UK, respectively, and Bradley and Migali (2015), who examine the impact of tuition fees on the dropout risk, also for the UK. In this latter study, the authors suggest that increased tuition fees actually encourage greater academic effort on the part of students in an attempt to maximise the return on their investment, resulting in a lower dropout risk. ${ }^{3}$

Although related to our research question, our aim in this paper is not to evaluate the

\footnotetext{
${ }^{3}$ An earlier paper by Deming and Dynarski (2009) provides a complete review of studies on the impact of student aid on enrolment decisions. They conclude that the results are highly dependent on the form of the reward or the design of the intervention.
} 
effects of the Spanish fee rise on enrolment or dropout behaviour, though, as mentioned above, we check the robustness of our main results to possible selection of students through these mechanisms. Instead, we are more interested in that other strand of the literature that analyses how tuition fees affect students' effort and, thus, academic achievement.

The interest in how effective financial and tuition aid is in improving students' academic achievement is relatively recent (Ashworth et al. 2002; Kremer et al 2009; Dynarski, 2008; Angrist and Lavy, 2009; Angrist et al. 2009). Many of the related contributions come, on the theoretical front, from behavioural economics theories and, on the empirical one from field experiments where students are given achievement-contingent rewards. An earlier paper by Camerer and Hogarth (1999) reviewed a wide set of studies in which individuals are paid financial rewards for a variety of tasks. According to these authors, it is difficult to draw conclusions because results are highly dependent on aspects such as intrinsic motivation and the students' ability that in some cases is needed to earn the reward.

A more recent study by Leuven et al. (2010) reports the results of an experiment among first-year students in economics and business at the University of Amsterdam. Students are classified into either a high reward group or a low reward one depending on the number of credits they collect in one year. The largest reward is given on completion of all first-year credits. They find positive effects on the achievement of high-ability students, whereas the impact is negative for low-ability students. According to the authors, their results are in line with the theory that external rewards may be detrimental to intrinsic motivation.

Also based on a field experiment, Ketel et al. (2016) test for the so-called sunkcost effect, which predicts that students paying more for certain tutorial sessions will be more willing to attend them and will, therefore, perform better. However, they do not find support for this hypothesis for their full sample, only for the subsample of students classified as sunk-cost prone.

In the study of Groen et al. (2008), the authors find a modest impact of a specific financial aid programme in reducing attrition rates and times-to-degree and, thus, in increasing completion rates. The impacts, however, are not directly attributable to greater student effort but appear to have been driven by reductions in entering cohort size and improved student quality. In the context of tuition fees and student performance, the paper by Garibaldi et al. (2012) about college costs and time to complete a degree raises the question of how the probability of late graduation would be reduced if continuation tuition were raised. Using data from a private institution (Bocconi University in Italy, during the period 1992-2002), where students are assigned different tuition fee levels depending on their family income, the authors use a regression discontinuity design to 
show that if a student's tuition fees increased by 1,000 euros in the previous year, the probability of late graduation would fall by 5.2 percentage points.

The contribution that our analysis makes to the existing subject literature is threefold. First, we add both a theoretical analysis and fresh empirical evidence that enrich the still scarce literature on the potential impact of tuition fees on student effort. Second, we investigate the effects of a tuition fee structure that is quite unique in the world. Students register and pay for their chosen modules, and the price of each module is set according to the number of credits awarded and the number of times the student has taken it. Although we use data from one particular university, this same general scheme is in place in all public universities in Spain. Finally, we use an unusually rich data set that offers some advantages over other studies. In particular, observations in our data sample refer to students in a given module and year. Each student contributes the same number of observations to our estimation sample as modules that the student is or has been enrolled in over the sample years. Thus, this data structure provides much higher variation to analyse students' responses and, in particular, it shows possible marginal adjustments by students at the module level.

From a policy point of view, our paper shows the importance of thinking about the particular design of tuition fee structure in higher education. Better academic grades and savings in terms of the number of times students take modules before graduating, which is to say higher efficiency in the use of educational resources, seem desirable targets of the educational policy.

\section{A model of student effort}

In this section we introduce a simple model of student effort to illustrate theoretically the likely implications of a rise in university tuition fees. The model includes the key elements of the tuition fee structure in public universities in Spain. Our model shows that the increase in tuition fees may produce heterogeneous responses depending on each student's individual ability. In particular, under a reasonable set of assumptions, it predicts that the probability of passing the exams will increase, especially for lower ability students, when tuition fees are raised following a pattern similar to the one recently implemented in Spain. The model thus provides a conceptual framework to interpret the empirical findings in the next section. 


\subsection{Model set-up}

The model is rooted in the Beckerian tradition of time allocation between leisure and study (see Becker 1965). To keep things simple, we assume that all the action takes place in one period. ${ }^{4}$ At the beginning of the period the student enters university endowed with initial income $y$ and ability $\widetilde{\mu}$. We do not consider the student's enrolment decision. The term $y$ can be thought of as capturing the fallback position in terms of income, which includes expected labour income after completing secondary education plus the present value of all family transfers during the student's lifetime. As in Lochner and MongeNaranjo (2011), $\widetilde{\mu}$ stands for innate factors, early parental child motivation, and other characteristics that determine academic success.

In our model, a period at university implies a minimum amount of tuition payments $(m)$. At the end of this period the student takes an exam with a level of difficulty $\mu^{\prime}$, which may vary among university degrees. If they pass, they get a first class $(F C)$ certificate. If they fail, they incur a cost overrun and obtain a second class $(S C)$ certificate. Given the student's inherent ability and the difficulty level of the exam, the probability of getting a FC degree is a function of the student's effort $(s)$. Effort is interpreted as units of time devoted to study, both class time and private study, so leisure $(l)$ is a negative function of effort $l=h-s$, where $h$ represents total time available.

It is assumed that a student who enters the university will end up obtaining their degree (with an $F C$ or an $S C$ certificate) at the end of the period. We do not consider dropouts. Income at the end of the period proxies for future income, and is contingent on the type of certificate the student gets, which, in turn, depends on time-to-completion. The model therefore captures the idea that early completion sends an important signal to those making hiring decisions in the labour market.

In order to choose the optimal effort level the student seeks to maximise the expected utility, which depends on the amount of consumption $(c)$ and leisure $(l)$. When making this choice, the student faces two possible regimes:

- They obtain an FC certificate with probability $F(\mu, s)$, with their consumption then becoming $c_{1}=y_{0}+s^{\beta}+b-m$.

- They obtain an SC certificate with probability $1-F(\mu, s)$, and then their consumption becomes $c_{2}=y_{0}+s^{\beta}-(2 m+d)$.

\footnotetext{
${ }^{4}$ Bolli and Johnes (2015) also use a static model of student time to examine the effects of changes in class time and tuition fees on student effort. In a more dynamic environment, an equivalent setting would be one where the student decision implies full commitment and all the exogenous variables, conditional on the effort choice, are constant over time.
} 
In the previous expressions, $s^{\beta}$ (with $\beta$ positive) represents the income premium for completing a degree. The implicit assumption -although it is not crucial to our resultsis that the student's university studies are indicative of the level of effort they can be expected to exert later in the labour market, which is a key factor determining future income. Income after degree completion is additionally augmented by $b$ when the student is awarded with an FC certificate. If the student fails the final exam, they have to pay the tuition fees again plus an extra cost $d$. The total cost penalty for failing to get an FC certificate (i.e., the incremental cost of an SC certificate) is then $m+d$. This feature of the model is akin to the tuition fee structure at Spanish universities.

The probability of successfully achieving an FC degree, for a given ability $\widetilde{\mu}$ and difficulty level $\mu^{\prime}$, is assumed to follow a sigmoid function of effort, $s$. In particular, we assume a generalised logistic function bounded at 1 , with location parameter $\mu$ (and scale parameter assumed to be 1 and omitted in notation): ${ }^{5}$

$$
F(\mu, s)=\frac{1}{1+e^{-(s-\mu)}}
$$

Intuitively, we assume that $\mu$ decreases with ability and increases with the level of difficulty:

$$
\mu=g\left(\begin{array}{cc}
\widetilde{\mu}, & \mu^{\prime} \\
- & +
\end{array}\right)
$$

Figure 1 represents the probability of getting an FC certificate as a function of effort, assuming total time available $h=10$. The three lines correspond to $\mu=3$ (dotted line); $\mu=5$ (solid line); and $\mu=7$ (dashed line). Compared with $\mu=7$, a value of $\mu=3$ can represent a more capable student or an easier degree, both of which increase the probability of getting an FC certificate for a given level of effort. Keeping the complexity of the university degree constant, the probability $F$ for a high ability student moves with effort along the dotted line. Conversely, for a given ability, the probability of obtaining an FC certificate in a more difficult degree moves along the dashed line.

Assuming a Cobb-Douglas type utility function with consumption preference parameter $\alpha$, the student optimisation problem can be written as follows:

$$
\begin{gathered}
\max _{s} E[U(c, l)]=F(\mu, s)\left(y_{0}+s^{\beta}+b-m\right)^{\alpha}(h-s)^{1-\alpha}+ \\
(1-F(\mu, s))\left(y_{0}+s^{\beta}-(2 m+d)\right)^{\alpha}(h-s)^{1-\alpha}
\end{gathered}
$$

\footnotetext{
${ }^{5}$ S-shaped functions also support the specification of the probability in empirical models of binary choices such as logit and probit models.
} 
s.t.

$$
0 \leqslant s \leqslant h
$$

Figure 1: Probability of getting an FC certificate for $\mu=3,5,7$.

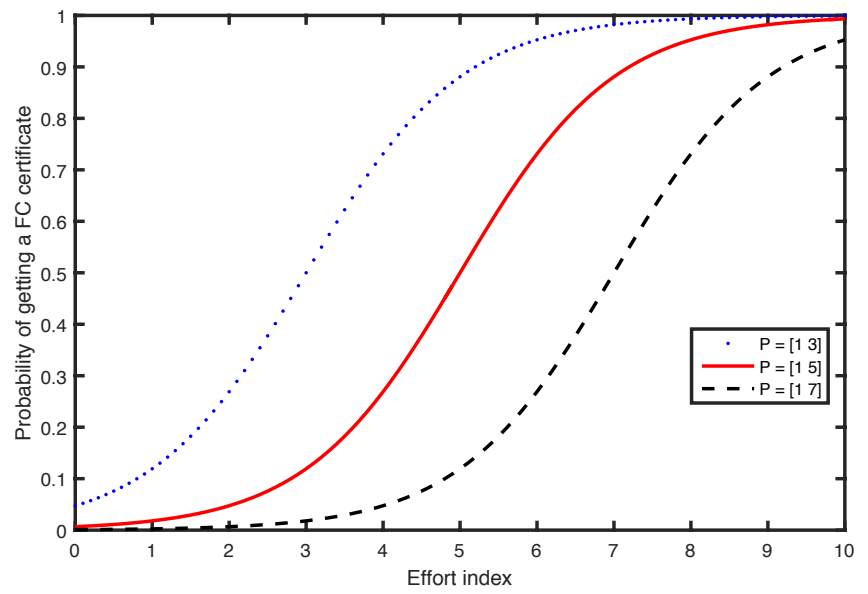

This problem implies the choice of effort depending on parameters $\mu$ (ability/difficulty), $y_{0}$ (fallback income), $\beta$ (minimum return to effort), $b$ (FC premium), $\alpha$ (consumption/leisure preference), $m$ (tuition fees) and $d$ (SC extra cost penalty). The first order condition takes the form:

$$
\begin{aligned}
& {\left[\begin{array}{c}
F_{s}(\mu, s) c_{1}^{\alpha}+\alpha c_{1}^{\alpha-1} \beta s^{\beta-1} F(\mu, s) \\
-F_{s}(\mu, s) c_{2}^{\alpha}+\alpha c_{2}^{\alpha-1} \beta s^{\beta-1}(1-F(\mu, s))
\end{array}\right](h-s)^{1-\alpha}} \\
& -(1-\alpha)(h-s)^{-\alpha}\left[F(\mu, s) c_{1}^{\alpha}+(1-F(\mu, s)) c_{2}^{\alpha}\right]=0
\end{aligned}
$$

where $F_{s}(\mu, s)$ represents the first derivative of $F(\mu, s)$ with respect to $s$. Equation (1) does not admit a closed solution and hence we rely on numerical solutions, which we present below.

\subsection{Model solution}

To obtain a numerical solution of the model we first need to provide values for its parameters. These values were, as explained in the appendix, determined based on the actual tuition fees at UV, observed sample probabilities of passing and other reasonable assumptions. These parameter values are displayed in Table 2, and the corresponding model solution is displayed in Table 3. The first row contains the benchmark solution, while the rest of the table checks the reaction of the model to changes in the parameter values. In 
Table 2: Parameter values

\begin{tabular}{lllllllll}
\hline \hline$y_{0}$ & $h$ & $\beta$ & $b$ & $\alpha$ & $\gamma$ & $m$ & $d$ & $\mu$ \\
10 & 10 & 0.15 & 10 & 0.61 & 0.8 & 0.53 & 0.30 & 6.6 \\
\hline
\end{tabular}

Table 3: Model solution

\begin{tabular}{lcc}
\hline \hline & Student's effort & Prob FC degree \\
Benchmark & $\mathbf{6 . 5 5}$ & $\mathbf{4 8 . 7}$ \\
$y_{0}=10 \rightarrow 9$ & 6.71 & 52.9 \\
$\beta=0.15 \rightarrow 0$ & 6.58 & 49.5 \\
$b=10 \rightarrow 11$ & 6.69 & 52.2 \\
$\alpha=0.61 \rightarrow 0.63$ & 6.73 & 53.1 \\
$m=0.53 \rightarrow 0.81$ & 6.68 & 52.0 \\
$d=0.3 \rightarrow 1.75$ & 6.92 & 57.8 \\
$\mu=6.6 \rightarrow 6.0$ & 6.32 & 57.9 \\
\hline
\end{tabular}

the benchmark solution, the student devotes 65 percent of their time to study (35 percent to leisure) and the probability of getting an FC certificate is 48 percent (according to the available sample information). From the sensitivity analysis we conclude that a decrease in fallback income $y_{0}$ (due, for instance, to a less affluent family environment) or a reduction in parameter $\beta$ tend to increase the student's effort. The rationale behind these results is that the lower that part of lifetime income that is independent of getting an $\mathrm{FC}$ or an $\mathrm{SC}$ degree, the larger the relative value of the income premium of an $\mathrm{FC}$ degree and, thus, the larger the effort to obtain it. An increase in the income premium for an early completion, $b$, has a similar qualitative effect. As expected, a rise in the preferences for consumption also pushes up both effort and the probability of obtaining an FC certificate. As for the cost of enrolment, we increase the two parameters $m$ and $d$ according to the 2012 fee rise, and the results clearly point to a positive effect on both study time and early completion. However, a fall in $\mu$, representing a more able student or a less difficult degree, would allow for a reduction in study time while increasing the probability of getting an FC certificate.

Figure 2 represents the theoretical effect of the 2012 fee rise on the change in probability of early completion as a function of the student ability for a given degree (or level of difficulty). High ability students (low value of $\mu$ ) have a high probability of early completion and, thus, do not find it so worthwhile to make greater effort when tuition fees and, in particular, the step penalty $d$ increase. However, less able students (a higher value of $\mu$ ) face a high probability of a notable cost upturn if they fail, but they still have a margin to increase the part of their time allocated to study. Hence, what Figure 2 reflects is that 
the policy under study can actually generate a heterogeneous response in terms of effort, and that the probability of passing the exams at the first attempt is expected to increase more for less able students than for highly able ones.

Thus, our theoretical model suggests two empirically testable hypotheses. The first is that an increase in tuition fees tends to increase academic effort on the part of university students. The second is that this response is expected to be greater in the case of average/low ability students than in the case of top students. In the following two sections we turn to their empirical analysis.

Figure 2: Heterogeneity in the response to an increase in tuition fees.

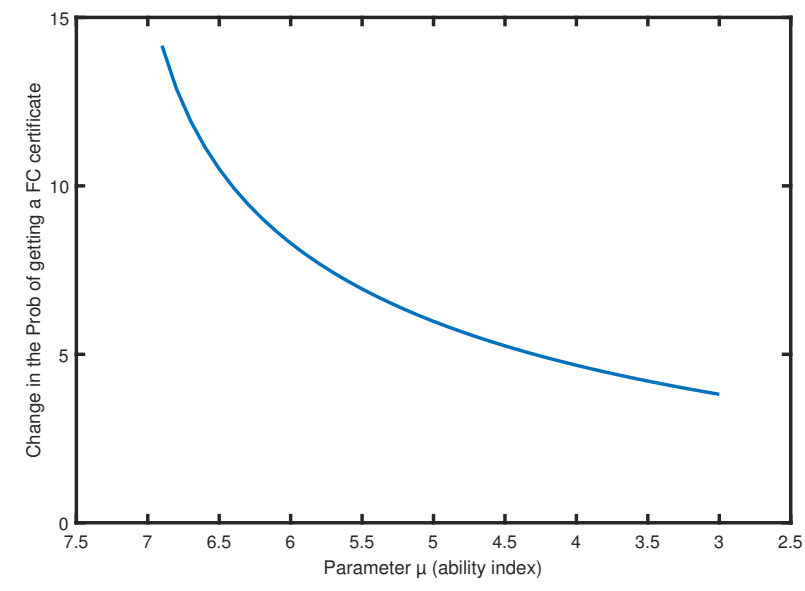

\section{Data: Economics, Business and Medicine Students at the Uni- versity of Valencia}

The University of Valencia, with more than 50,000 students in 2016, is one of the largest public universities in Spain. Following a formal request for information relevant to the present research study, UV provided us with data for all students enrolled in economics, business and medicine at UV from 2010 to 2014. For all these students we received anonymised administrative records containing information on each student's entrance grade, the educational level and employment status of their father and mother, the student's employment status, type of registration made by the student for each module (full payment, partial payment, exempt), modules that the student is or has been enrolled in over the sample years, exams taken each year (per module) and the grades achieved, as well as certain demographic characteristics such as gender and age.

Unlike in many other higher education systems around the world, UV students do not 
pay a fixed amount per year of enrolment. Instead, they register and pay tuition fees for a number of modules, and the price of each one is set according to the number of credits the module offers and the number of times the student has taken the module (see Table 1 in the Introduction). Students are allowed to take the final examination of a module twice per paid registration (i.e., they have two 'chances' per payment). It can be difficult to determine which year of their degree students are in when, for instance, the student is concurrently taking first-, second- and third-year modules in a given academic year. In fact, in our data sample, each observation refers to one student in a given module and degree year. Each student contributes the same number of observations to our estimation sample as modules that the student is or has been enrolled in over the sample years (multiplied by two for those modules where the student has taken the exam twice). That is, we include not only summary information of a student's performance in a given academic year, but also their performance in all the modules they have taken over the sample period.

In our econometric setting we exploit the fact that there are different tuition fee regimes for different groups of UV students. On the one hand, around 65 percent of students have to pay tuition fees in full. We call these 'regular registration' students. Conversely, around 4 percent of students are 100 percent exempt from fees. These totally exempt students may belong to any of the following three categories: students from large families of five or more siblings; students with an officially recognised degree of disability equal to or greater than 33 percent; or victims of terrorism. These three categories of students make up our control group in the estimation. We exclude all other students from our DID estimation sample, both from the treatment and from the control group. Some of these other students are either partially exempt (those from families with three or four siblings and from low-income families) or students on a grant. Students may also gain a total exemption in one module in the incoming academic year for each module in which they gained a Distinction in the previous year. In these cases, we exclude the information from the module that is free of charge. In addition, students who finish secondary school with an average grade of Distinction are exempt from payment for all the modules in the first year; we also leave these observations out of our analysis. Finally, we also disregard Erasmus students because their enrolment schedule is different.

Our strategy to identify the causal effect of the fee rise is based on a difference-indifferences regression (DID, explained further in next section), where we follow the behaviour of regular registration students as compared to the behaviour of the three categories of totally exempt students over the period 2010-2014, and try to capture whether their comparative academic performance exhibits a change after the fee rise in 2012 . The 
rationale behind the DID regression, widely used in policy intervention analysis, lies in the fact that individuals who are not affected by the policy (control group) can be used as the counterfactual for those affected by the policy (treated individuals) once their idiosyncratic differing characteristics (which are allowed to exist) have been accounted for. In other words, apart from these time constant differences between treated and control individuals, the control group may reflect what the treated individuals would have done in the absence of the treatment. After the treatment, differences in the behaviour of treated as compared to control individuals beyond the normal differences exhibited in the pre-treatment period are interpreted as the causal effect of the treatment.

For a group of students to be valid as a control group, it must fulfil two conditions. First, students in the control group must not be affected in any way by the 'treatment' (fee rise). Second, assignment to the treatment group (and by extension to the control group) must be random. This means that a student's exempt status cannot be altered by the variables under scrutiny (i.e., the student's effort and any academic performance indicator used as a proxy for effort). That is, exemption must not be conditional on the student's academic performance, otherwise the student might react to the tuition fee rise precisely in order to prevent the loss of their exempt status. Hence, the totally exempt students defined above constitute a valid control group for our DID approach since they fulfil the two stated conditions. We discard students who are only partially exempt, since this group does not fulfil the first condition, and also students on a grant, since their grant (exemption) is based on their academic performance and, thus, they do not fulfil the second condition. We are aware that our control group may initially appear small compared to the size of the whole sample (around 4 percent). However, the number of observations for control students is still large, sufficiently so to follow the evolution of this group over our sample period. We thus consider it worth sacrificing a larger control group in favour of a more reliable one. ${ }^{6}$

Our final estimation sample is then composed of observations from regular registration students and totally exempt students over the period 2010-2014. Throughout the rest of the paper, we treat economics students and business students jointly in the analysis (although they are two distinct degrees at UV), and separately from medical students. The potentially different behaviour of economics-business students as compared to medical students, as well as the different tuition fee structures that apply in each case justify

\footnotetext{
${ }^{6}$ In the context of public health practices, Hutchings et al. (2015) show, across simulated studies, that the mean intervention effect and effect sizes were equivalent regardless of control group size. The authors conclude that studies with small control groups can generate evidence that is as valid and accurate as with larger control samples.
} 
Table 4: Comparison of treated and control groups before and after 2012 fee rise

\begin{tabular}{|c|c|c|c|c|c|c|c|c|}
\hline & \multicolumn{4}{|c|}{ ECONOMICS and BUSINESS } & \multicolumn{4}{|c|}{ MEDICINE } \\
\hline & \multicolumn{2}{|c|}{ Before } & \multicolumn{2}{|c|}{ After } & \multicolumn{2}{|c|}{ Before } & \multicolumn{2}{|c|}{ After } \\
\hline & Treated & Control & Treated & Control & Treated & Control & Treated & Control \\
\hline Number Observations & 88363 & 1716 & 120230 & 2987 & 24710 & 2175 & 44769 & 4591 \\
\hline Students' Age (sample average) & 23 & 23 & 21 & 22 & 24 & 26 & 22 & 25 \\
\hline Grades of graduation from high-school* & 7.00 & 7.42 & 7.98 & 8.27 & 11.40 & 11.40 & 12.69 & 12.00 \\
\hline \multicolumn{9}{|l|}{ Percentage of all observations who: } \\
\hline - Are females & 46.8 & 36.3 & 45.8 & 40 & 68.5 & 66.7 & 65.3 & 65.8 \\
\hline - Are full-time students (no work) & 76.2 & 75.8 & 79.2 & 81.7 & 83.1 & 83.8 & 85.1 & 80.2 \\
\hline - Have father/mother with no-education or primary & $30 / 33$ & $16 / 19$ & $30 / 31$ & $21 / 18$ & $20 / 21$ & $19 / 19$ & $21 / 22$ & $16 / 17$ \\
\hline - Have father/mother with university education & $24 / 16$ & $43 / 31$ & $23 / 17$ & $36 / 26$ & $42 / 32$ & $47 / 32$ & $46 / 37$ & $45 / 33$ \\
\hline - Have father/mother without paid job & $9 / 33$ & $7 / 42$ & $12 / 31$ & $17 / 44$ & $8 / 28$ & $13 / 42$ & $8 / 26$ & $13 / 35$ \\
\hline - Have father/mother who work as civil servants & $36 / 27$ & $24 / 24$ & $34 / 28$ & $21 / 18$ & $27 / 26$ & $20 / 17$ & $29 / 29$ & $15 / 21$ \\
\hline - Have father/mother with unskilled jobs & $21 / 18$ & $14 / 14$ & $23 / 28$ & $21 / 19$ & $15 / 11$ & $18 / 11$ & $14 / 10$ & $21 / 15$ \\
\hline
\end{tabular}

examining them separately. In Table 4 we outline some general characteristics of the students in our estimation sample. The final sample of students-modules-year observations for economics-business is composed of 213,296 observations corresponding to 6,469 students, while for medicine the sample comprises 76,245 observations from 2,271 students.

The main difference between economics-business students and medical students is that the latter are required to achieve much higher entrance grades than the former. ${ }^{7}$ Specifically, over the period under study, the average entrance grade for medicine was above 11 on a scale from 0 to 14, whereas for economics and business the corresponding grade was around 7. Thus, the students that had the lowest grades for entering medicine had achieved, on average, much higher grades at secondary school than students entering economics-business. There are more women studying medicine (above 65 percent in all the categories) than economics and business (from 36 to 46 percent, depending on the case), and medical students are also slightly older (one reason being that medicine is a six-year degree while economics and business are four-year degrees). Also, more than 75 percent of students are full-time students, without paid jobs, with the percentages being even higher in the case of medicine (up to 85 percent). In general, differences between the treated and control students before and after 2012 do not seem to be worth noting.

The variables in our dataset that provide information about the educational and economic situation of the student's household are binary variables taking the value one whenever the parents have a given level of formal education or have a given employment

\footnotetext{
${ }^{7}$ The entrance grade refers to the specific numerical grade that students record on their university application. The number is obtained by averaging the student's grades achieved at secondary school and in a specific examination compulsory for enrolment in public universities in Spain. The final grade is numerically recorded on a scale from 0 to 14 , and every year faculties establish the minimum entrance grade for enrolment in a given degree. Over the last years, medicine has required the highest such marks, whereas for economics and business these marks are among the lowest at UV.
} 
status, and zero otherwise. For the educational variables, six possible levels of education are considered, ranging from no formal education to university education. As for the employment status variables, eight categories are considered, including no paid job, unskilled job and six more categories referring to the sector of activity where the student's parents work. All these educational and employment variables are given for the student's father and mother separately.

In Table 4 we provide information on the 'no formal education', 'no paid job' and 'unskilled jobs' categories, as well as on the most common of the other categories, namely 'parents with university education or working as civil servants'. Families where both parents lack formal education appear somewhat less frequently in medicine than in economicsbusiness and, in both disciplines, students in the control group fall into this category less frequently. Also, families in the upper tail of the education distribution appear more frequently in medicine, and among control students in economics-business. These characteristics, as expected, seem to remain quite stable over our period of study. As regards the employment status of the father and mother, the figures do not reveal any change in the sample for medicine after 2012 as compared with the previous years. In economics and business, however, a somewhat higher incidence of unemployed fathers is observed after 2012, for both treated and control students, although slightly higher for the latter group. In our econometric setting below, we do not allow these changes to confound the identification of the fee rise effects since all these characteristics are controlled for in the DID regressions.

Finally, in Table 5 we present some descriptive figures for the three variables we use to reflect changes in student effort as a response to the 2012 fee rise. In order to avoid paying twice (or more) for the credits of a module, the student will probably try to take as few exams as possible to pass the modules. Using the available information, we first construct a variable measuring the number of registrations that the student needed to pass a module (number of registrations before passing). Second, closely related to although slightly different from the first, we construct a binary variable taking the value one if the individual passes the exam with the first registration. Third, we analyse the impact on the grades (measured on a numerical scale ranging from 0 to 10) obtained by the student in a given module. Although for grades higher than a pass (5 out of 10 in a module) there are no additional gains in terms of tuition fee savings, we believe that a likely consequence of an increased effort to pass the modules as soon as possible would be the achievement of higher grades.

In Table 5 we distinguish between average and top students, since we focus on this distinction in the following section when detailing and interpreting our econometric results. 
Table 5: Descriptives of the main variables. Top and average students.

\begin{tabular}{lcccccc}
\hline \hline & \multicolumn{2}{c}{ ECONOMICS and BUSINESS } & \multicolumn{2}{c}{ MEDICINE } \\
& All Stud. & Averg. Stud. & Top Stud. & All Stud. & Averg. Stud. & Top Stud. \\
\hline Number Observations & 213296 & 170580 & 42716 & 76245 & 60908 & 15337 \\
Number Students & 6469 & 4933 & 2009 & 2271 & 1871 & 522 \\
Control group (N. Obs) & 4703 & 3552 & 1151 & 6766 & 5477 & 1289 \\
Number of registrations until pass & 1.45 & 1.50 & 1.25 & 1.15 & 1.18 & 1.09 \\
- Before fees rise (2010-2011) & 1.50 & 1.58 & 1.24 & 1.16 & 1.19 & 1.08 \\
- After fees rise (2012-2014) & 1.41 & 1.46 & 1.26 & 1.14 & 1.17 & 1.09 \\
Prob. of pass in 1 st registration $^{-1.40}$ & 0.47 & 0.45 & 0.53 & 0.70 & 0.70 & 0.71 \\
- Before fees rise (2010-2011) & 0.43 & 0.41 & 0.49 & 0.70 & 0.68 & 0.72 \\
- After fees rise (2012-2014) & 0.50 & 0.48 & 0.56 & 0.70 & 0.71 & 0.70 \\
Grades (if presented to the exam) & 5.29 & 5.18 & 5.74 & 6.55 & 6.42 & 6.84 \\
- Before fees rise (2010-2011) & 5.12 & 4.94 & 5.80 & 6.53 & 6.36 & 7.13 \\
- After fees rise (2012-2014) & 5.40 & 5.32 & 5.71 & 6.57 & 6.46 & 6.75 \\
\hline \multicolumn{2}{c}{ Average and top students are classified according to their entrance grades (an average of grades obtained in secondary school and } \\
in a specific examination compulsory for enrolment in public universities in Spain).
\end{tabular}

We consider top students those above the 80th percentile of the entrance grades distribution within each degree, whereas average students are those with entrance grades below that percentile. An initial observation from Table 5 is that, in general, medical students perform better than students of economics-business in all three indicators of academic performance: medical students need fewer registrations to pass modules, exhibit higher probability of passing with the first registration and obtain higher grades. The beforeafter comparisons of these indicators also point to a possible effect of the fee rise since most of the values of the three indicators appear to improve, albeit moderately, after 2012. The comparison between average and top students shows that students with better entrance grades also perform better during the degree, being these differences somewhat less pronounced between average and top students in medicine. A possible explanation for this latter finding lies in the high minimum grade required to enter medicine at UV, which means that average students in this degree may be very similar in terms of ability to top students.

At this descriptive level, however, we cannot state whether or not the observed differences are statistically significant. Neither can we rule out some effects that are not controlled for and that might be driving these apparent patterns. To control for these module-specific and other possible confounding effects we move to the econometric section below. 


\section{Estimation of the effects of the tuition fees-rise}

\subsection{Identification Strategy}

Ideally, the identification of the causal effect of any policy intervention would require the observation of what the individual would have done without the intervention, that is, the observation of the counterfactual. By definition, however, the counterfactual cannot be observed. The difference-in-differences approach tries to estimate how the treated (individuals subject to the treatment) and a control group (those not subject to the treatment) differ from one another, before and after the treatment. The DID approach is robust to idiosyncratic permanent differences between the treated and the control group. Once these time-constant differences have been accounted for in the estimation, the control group can be used to construct the counterfactual behaviour of the treated group.

Our strategy to identify the causal effect of the fee rise is based on this DID approach, where we exploit the fact that UV applies different tuition fee regimes to different types of students, as described in the previous section. In particular, we follow the behaviour of regular registration students as compared to the behaviour of totally exempt students over the period 2010-2014, and try to capture whether their comparative academic performance exhibits a change after the 2012 fee rise.

To be more precise, in its standard and simplest version, the DID regression equation can be written as follows:

$$
Y_{\text {imt }}=\alpha+\alpha^{D} D_{i}+\gamma \text { Post }_{t}+\gamma^{D} \text { Post }_{t} D_{i}+\gamma \mathbf{x}_{i t}+c_{m}+a_{i}+u_{i m t}
$$

where subscripts $i, m$ and $t$ denote the student, module and year, respectively. The dependent variable, $Y_{i m t}$, will be alternately replaced in the estimation by the number of paid registrations the student requires to pass a module, a binary variable equal to one if the student passes the module with the first registration, and the grades obtained. Post is a dummy-step variable taking the value one for all periods (years) after treatment, capturing all possible changes after treatment affecting treated and control students equally; $D_{i}$ is a dummy variable for treated students, capturing time-constant differences between treated and control individuals, if any; $\mathbf{x}_{i t}$ stands for a vector of all other control variables entering the estimation equation; finally, $c_{m}$ and $a_{i}$ stand for module- and student-fixed effects, respectively, and $u_{i m t}$ stands for the iid error of the model.

In equation (2), once post-treatment changes affecting both treated and control students as well as permanent differences between the two groups have been controlled for, 
parameter $\gamma^{D}$ identifies the treatment effect. The validity of the standard DID regression equation in (2) relies heavily on two assumptions that, in spite of the frequent use of this approach in empirical policy evaluation, are not frequently discussed in published research. The first of these assumptions is crucial to claim that parameter $\gamma^{D}$ identifies the effect of interest: prior to the treatment there must be no differences in trends between treated and control individuals. If this pre-treatment parallel paths assumption is violated, then increasing or decreasing differences between control and treated individuals after the treatment cannot be attributed to the treatment. The second assumption implicit in equation (2) is that the effects of the treatment appear as early as the first year post-treatment and, moreover, these effects do not differ over the years after the treatment. In other words, the effects of the treatment are assumed to be static.

The importance of checking for pre-treatment parallel paths, as well as allowing for dynamic effects after treatment is extensively discussed by Mora and Reggio (2012). The fully-flexible DID approach proposed by these authors allows us, first, to check for possible non-parallel pre-treatment trends and, second, to estimate dynamic effects after treatment. A fully-flexible DID regression equation in our setting can be written as follows:

$$
Y_{i m t}=\alpha+\alpha^{D} D_{i}+\sum_{\tau=t_{0}+1}^{T} \beta_{\tau} I_{\tau}+\sum_{\tau=t_{0}+1}^{T} \beta_{\tau}^{D} I_{\tau} D_{i}+\gamma \mathbf{x}_{i t}+c_{m}+a_{i}+u_{i m t}
$$

where $I_{\tau}$ is a dummy variable identifying year $\tau$ (with $\tau=2011,2012,2013,2014$, and $t_{0}=2010$ absorbed in the constant). With treatment occurring at $t^{*}$ (sometime before the beginning of academic course 2012-2013), checking that $\beta_{\tau}^{D}=0 \quad \forall \tau<t^{*}$ indicates no differences in pre-treatment trends. ${ }^{8}$ In the estimation, provided that there are in fact no such differences, parameters $\beta_{\tau}^{D}$ identify the treatment effects for $\tau \geqslant t^{*}$.

\subsection{Econometric results}

We apply equation (3) alternately to the three indicators of students' response to the tuition fee rise described above. As explicitly recognised in equation (3), both module- and student-specific fixed effects could be affecting the observed indicator of student performance. Ideally, we want to identify as closely as possible how the same student in the same module would behave before and after the fee rise, as compared to a control classmate. In

\footnotetext{
${ }^{8}$ If pre-treatment trends were not parallel, one way to deal with this would be to take differences of the dependent variable and apply the DID regression to this transformed variable until we obtain evidence of no differences in the pre-treatment trends (differences-in-double-differences).
} 
other words, we are interested in exploiting the within-student and within-module time variation in the data to identify the effect of interest, while ruling out unobserved heterogeneity across students and modules. For this purpose, we apply the two high-dimensional fixed effects regression model proposed by Guimaraes and Portugal (2010) to our DID equation above, for all three alternative indicators used. ${ }^{9}$

As with the standard linear panel data fixed effects model, the effect of those variables with no time variation either within-student or within-module cannot be identified. This includes idiosyncratic differences between treated and control individuals, as well as students' socio-economic characteristics and/or those of their family, which remain invariant in time. The estimation, nonetheless, is robust to the exclusion of these variables from the analysis. Hence, in the estimation, we remove the term $\alpha D_{i}$ from the equation, since the students' fixed effects control all the across-student heterogeneity, including constant differences between treated and control students. Also, constant variables such as the student's age (at the beginning of the degree) and gender are left out. Finally, among the rest of the control variables potentially entering vector $\mathbf{x}_{i t}$, we include the dummy variables accounting for the student's employment status and the economic situation of the father and mother, while the educational level variables for the father and mother are dropped from the estimation since they do not exhibit time variation.

The estimation results corresponding to the three indicators mentioned above are provided in Tables 6 to 8. First, the DID estimation of the number of times the student has paid for a module before passing it is presented in Table 6. In the table results are given for economics-business and for medicine students separately. In both cases the DID equation has been estimated first for all students and then distinguishing between average and top students. A first result is that the average number of times a student registered in 2011 does not significantly differ between treated and control students as compared to the initial year, 2010. As indicated above, the fact that the coefficient for treated students in 2011 does not differ statistically from zero is essential in the DID analysis in order to claim that the coefficients of the rest of the treated-year crossed dummies identify the fee rise effect.

The results provided in the first column for economics-business students suggest that

\footnotetext{
${ }^{9}$ The method developed by Guimaraes and Portugal (2010) is an iterative approach for the estimation of linear regression models with more than one high-dimensional fixed effect, where explicit introduction of dummy variables is not an option because the number of units (groups) is too large. This is the case with our analysis, where we want to simultaneously account for two sources of unobserved heterogeneity, the module and the student. Although computationally intensive, this method has the advantage of imposing minimal memory requirements. Results are equivalent to introducing as many dummy variables as units in the regression, but it does not require the inversion of such large matrices.
} 
Table 6: Number of registrations before passing. Fully flexible DID regression.

\begin{tabular}{|c|c|c|c|c|c|c|}
\hline & \multicolumn{3}{|c|}{ ECONOMICS and BUSINESS } & \multicolumn{3}{|c|}{ MEDICINE } \\
\hline & All Stud. & Averg. Stud. & Top Stud. & All Stud. & Averg. Stud. & Top Stud. \\
\hline \multirow[t]{2}{*}{ Year 2011} & $0.629^{* * *}$ & $0.606^{* * *}$ & $0.503^{* * *}$ & $0.449^{* * *}$ & $0.447^{* * *}$ & $0.453^{* * *}$ \\
\hline & $(0.030)$ & $(0.038)$ & $(0.077)$ & $(0.022)$ & $(0.026)$ & $(0.031)$ \\
\hline \multirow{2}{*}{ Year 2012} & $1.248^{* * *}$ & $1.286^{* * *}$ & $1.114^{* * *}$ & $0.797^{* * *}$ & $0.804^{* * *}$ & $0.872^{* * *}$ \\
\hline & $(0.028)$ & $(0.038)$ & $(0.042)$ & $(0.024)$ & $(0.029)$ & $(0.040)$ \\
\hline \multirow[t]{2}{*}{ Year 2013} & $1.851^{* * *}$ & $1.906^{* * *}$ & $1.502^{* * *}$ & $1.312^{* * *}$ & $1.325^{* * *}$ & $1.255^{* * *}$ \\
\hline & $(0.025)$ & $(0.027)$ & $(0.040)$ & $(0.031)$ & $(0.035)$ & $(0.061)$ \\
\hline \multirow[t]{2}{*}{ Year 2014} & $2.410^{* * *}$ & $2.453^{* * *}$ & $2.175^{* * *}$ & $1.609^{* * *}$ & $1.595^{* * *}$ & $1.683^{* * *}$ \\
\hline & $(0.029)$ & $(0.028)$ & $(0.037)$ & $(0.038)$ & $(0.045)$ & $(0.060)$ \\
\hline \multirow[t]{2}{*}{ Treated in Year 2011} & -0.036 & -0.001 & 0.031 & -0.023 & -0.021 & 0.046 \\
\hline & $(0.030)$ & $(0.037)$ & $(0.077)$ & $(0.021)$ & $(0.024)$ & $(0.029)$ \\
\hline \multirow[t]{2}{*}{ Treated in Year 2012} & $-0.103^{* * *}$ & $-0.114^{* * *}$ & -0.062 & -0.016 & -0.019 & 0.022 \\
\hline & $(0.027)$ & $(0.037)$ & $(0.040)$ & $(0.019)$ & $(0.022)$ & $(0.024)$ \\
\hline \multirow{2}{*}{ Treated in Year 2013} & $-0.171^{* * *}$ & $-0.188^{* * *}$ & 0.017 & $-0.085^{* * *}$ & $-0.093^{* * *}$ & 0.045 \\
\hline & $(0.021)$ & $(0.024)$ & $(0.022)$ & $(0.020)$ & $(0.023)$ & $(0.045)$ \\
\hline \multirow[t]{2}{*}{ Treated in Year 2014} & $-0.215^{* * *}$ & $-0.213^{* * *}$ & $-0.172^{* * *}$ & $-0.041^{*}$ & -0.027 & -0.042 \\
\hline & $(0.024)$ & $(0.024)$ & $(0.020)$ & $(0.023)$ & $(0.026)$ & $(0.041)$ \\
\hline N Obs & 85575 & 65775 & 19800 & 46488 & 38961 & 7527 \\
\hline $\mathrm{R}^{2}$ & 0.705 & 0.715 & 0.630 & 0.581 & 0.577 & 0.628 \\
\hline
\end{tabular}

there is a clear effect of the fee rise in the expected direction. The negative estimated signs of the coefficients and their statistical significance indicate that, from 2012 to 2014, treated students in economics-business required fewer registrations to achieve a pass in the corresponding module than control students did. The coefficients also suggest that the effect steadily increased over the three years following the fee rise. As compared to 2010, in 2012 the average number of times that a regular student paid, or registered, for a module was around 0.10 lower than that of an exempt student. The difference is up to 0.17 registrations in 2013, and around 0.22 in 2014. Our theoretical prediction that the effort students make to pass a module probably increases more in the case of average students is also confirmed by the results in Table 6 . In fact, the results obtained for the full sample of students are almost replicated with the sample of average students, while in the case of top students the effects seem to be much less pronounced: it is only in 2014 that the treatment effect is found to be statistically significant, and of lower magnitude than for average students. ${ }^{10}$

\footnotetext{
${ }^{10}$ The estimated coefficients for the individual year dummies in Table 6 would suggest a positive trend in the number of registrations over time. However, such an interpretation is misleading in our context. The reason is that, in the two high-dimensional fixed effects regression, the method estimates, first, the
} 
The magnitude of these estimated effects can be interpreted relative to the descriptive figures in Table 5, where the sample average for the number of registrations is around 1.5 in economics-business. This indicates that these students need 0.5 additional registrations to pass a module. Broadly speaking, it is as though for each six-credit module taken before 2012, the student had to pay as many as 9 credits to pass it, that is, an excess of 3 credits (paid, at the very least, at the price for a second registration). After 2012, the average number of registrations has fallen to somewhat below 1.3. This implies students have reduced those excess credits to around 1.8 credits (a decrease of more than 40 percent), which, translated into monetary units, represents savings of 52 euros per module according to the fees listed in Table 1 in the Introduction. If, as Law 14/2012 states, tuition fees paid by the student for a second registration should cover between 30 to 40 percent of the total cost, then our estimates also indicate important savings for public universities.

When we look at the results for medicine, we also find negative and significant differences between treated and control students in the years after the fee rise. The column corresponding to the full sample of students shows the expected effects, although they are significant only in 2013 and 2014 (though less so in 2014). Once again, the results seem to be driven mainly by the behaviour of average students; the negative effect found in 2013 is only significant for this group of students. The group of top students, by contrast, has not responded to the fee rise, according to the estimates in the last column. In addition, although our theoretical analysis above is not conclusive as regards how the responses of medical students compare to economics-business students, the results suggest that students in these latter degrees have increased their levels of effort to a greater extent than students in medicine have. ${ }^{11}$

Next, in Table 7, we present the estimation results for the binary indicator variable that reflects whether the student passes a given module with the first registration (taking the value one if the module is passed with the first registration, and zero otherwise). The (two high-dimensional fixed effects) regression analysis applied to this binary variable should

module- and student- fixed effects and, then, it includes them as additional regressors in the equation. Thus, each module and individual has a different constant in the estimation model. Since students and modules in the sample vary over time, the mean value of the fixed effects also varies over the years. As a result, the mean value of the dependent variable changes over the years, not only as indicated by the year dummies coefficients, but also with the mean values of the fixed effects. In particular, the estimated time trend for the number of registrations in Table 6 turns out to be decreasing if we compute the mean values of the dependent variable including the mean fixed effects. This, however, does not interfere with the interpretation of the treatment effects.

${ }^{11}$ In terms of Figure 1, on the one hand, the greater difficulty of a degree in medicine would move the curve to the right, while, on the other hand, the higher ability of students entering medicine at UV would move it to the left. As a result, it is difficult to theoretically predict in which degrees - economics-business or medicine - students should be expected to be more responsive to the fee rise. 
be interpreted as a linear probability model (where module and student heterogeneity has been removed). ${ }^{12}$ Of course, our two variables 'number of registrations' and 'probability of passing with the first registration' are closely related to one another, although the information they contain is not necessarily redundant. The distinction could be important if, for instance, the probability of passing with the first registration did not change but the response for second, third and subsequent registrations became increasingly clear. The results in Table 7 again confirm that differences between treated and control students are not significant before 2012, thus ruling out the concern of pre-treatment non-parallel paths. The expected signs of the treatment effects are in this case positive, that is, a higher probability of passing after the fee rise for treated students.

The results for economics-business point to the fact that students who pay tuition fees have increased their efforts to pass the modules with the first registration, surpassing the efforts made by exempt students. The effects are statistically significant in 2013 and 2014, but only in the first two columns, thus indicating that this behavioural change is only displayed by average students. The magnitude of the estimated effects is around an 8 to 10 percent increase in the probability of passing with the first registration. As an example, with this increase, the probability of passing with the first registration for an average student in economics-business would change from the sample average of 41 percent before 2012 (see Table 5) to somewhere between 49 and 51 percent. In other words, average students adjust their academic effort such that they almost catch up with their top students counterparts in terms of probability of passing with the first registration (figures in Table 5 show a probability of 56 percent for top students in economics-business after 2012).

As for students in medicine, the estimates in Table 7 are only statistically significant in 2012, the first year after the fee rise and, once again, the effects seem to correspond to the sample of average students. The magnitude of the effects is appreciably smaller than for economics-business (a probability of around 5 percent). We do not have a compelling explanation for the fact that significant effects are only found in 2012. Perhaps the safest conclusion is that, overall, the effects have been almost negligible in medicine, with modest adjustments on the part of average students appearing right after the implementation of the fee rise. In any event, what this analysis clearly indicates is the appropriateness of implementing a fully flexible DID approach to our data, since there is evidence that the

\footnotetext{
${ }^{12}$ Under very general conditions, the average partial effects obtained in the linear estimation of a binary variable are closely similar to the marginal effects (evaluated at the sample averages of variables) obtained from other binary response models such as probit estimation. The linear specification has the advantage of enabling the straightforward application of the two high-dimensional linear fixed effects approach.
} 
Table 7: Passing with first registration. Fully flexible DID regression.

\begin{tabular}{|c|c|c|c|c|c|c|}
\hline & \multicolumn{3}{|c|}{ ECONOMICS and BUSINESS } & \multicolumn{3}{|c|}{ MEDICINE } \\
\hline & All Stud. & Averg. Stud. & Top Stud. & All Stud. & Averg. Stud. & Top Stud. \\
\hline \multirow[t]{2}{*}{ Year 2011} & $-0.092^{* * *}$ & $-0.086^{* * *}$ & $-0.102^{* * *}$ & -0.011 & -0.012 & -0.007 \\
\hline & $(0.020)$ & $(0.026)$ & $(0.031)$ & $(0.014)$ & $(0.015)$ & $(0.031)$ \\
\hline \multirow{2}{*}{ Year 2012} & $-0.203^{* * *}$ & $-0.191^{* * *}$ & $-0.241^{* * *}$ & $-0.019^{*}$ & $-0.032^{* *}$ & 0.028 \\
\hline & $(0.020)$ & $(0.025)$ & $(0.035)$ & $(0.012)$ & $(0.013)$ & $(0.025)$ \\
\hline \multirow[t]{2}{*}{ Year 2013} & $-0.364^{* * *}$ & $-0.351^{* * *}$ & $-0.381^{* * *}$ & $0.071^{* * *}$ & $0.074^{* * *}$ & $0.060^{* * *}$ \\
\hline & $(0.018)$ & $(0.019)$ & $(0.045)$ & $(0.012)$ & $(0.013)$ & $(0.022)$ \\
\hline \multirow[t]{2}{*}{ Year 2014} & $-0.418^{* * *}$ & $-0.401^{* * *}$ & $-0.412^{* * *}$ & $0.160^{* * *}$ & $0.169^{* * *}$ & $0.124^{* * *}$ \\
\hline & $(0.016)$ & $(0.017)$ & $(0.053)$ & $(0.013)$ & $(0.015)$ & $(0.021)$ \\
\hline \multirow[t]{2}{*}{ Treated in Year 2011} & 0.012 & 0.018 & -0.020 & -0.001 & 0.001 & -0.010 \\
\hline & $(0.020)$ & $(0.026)$ & $(0.030)$ & $(0.014)$ & $(0.015)$ & $(0.032)$ \\
\hline \multirow[t]{2}{*}{ Treated in Year 2012} & 0.032 & 0.037 & 0.012 & $0.042^{* * *}$ & $0.050^{* * *}$ & 0.013 \\
\hline & $(0.020)$ & $(0.025)$ & $(0.035)$ & $(0.011)$ & $(0.013)$ & $(0.024)$ \\
\hline \multirow[t]{2}{*}{ Treated in Year 2013} & $0.081^{* * *}$ & $0.080^{* * *}$ & 0.055 & 0.015 & 0.012 & 0.028 \\
\hline & $(0.017)$ & $(0.019)$ & $(0.044)$ & $(0.011)$ & $(0.013)$ & $(0.022)$ \\
\hline \multirow[t]{2}{*}{ Treated in Year 2014} & $0.091^{* * *}$ & $0.102^{* * *}$ & -0.005 & -0.006 & -0.015 & 0.032 \\
\hline & $(0.015)$ & $(0.016)$ & $(0.053)$ & $(0.012)$ & $(0.014)$ & $(0.021)$ \\
\hline N Obs & 107055 & 82016 & 25039 & 60218 & 49010 & 11208 \\
\hline $\mathrm{R}^{2}$ & 0.254 & 0.249 & 0.261 & 0.434 & 0.419 & 0.455 \\
\hline
\end{tabular}

treatment effects may not be equally distributed over time after the treatment.

The estimation results for our third indicator of academic performance, grades, are displayed in Table 8. Although a natural outcome of students making greater academic effort would be an increase in grades, the fee rise might not translate into higher grades if students switched their academic goals from obtaining good grades to passing the modules as fast as possible in a given academic year. If this was the case, it would cast doubt on the net efficiency effects of the fee rise (similar to the collateral effects pointed out by Garibaldi et al., 2012, of trying to graduate on time at the expense of the quality of the learning process). Results in Table 8, however, allow us to rule out this concern: positive treatment effects are found both in economics-business and in medicine, which are captured significantly in 2013 and 2014 for the former and from 2012 onwards for the latter.

Turning to the differences between average and top students in Table 8, we observe a pattern that contrasts with the results in Tables 6 and Table 7 above, since it seems that, in general, top students register a more marked response to the rise in tuition fees in terms of academic grades. In the case of economics-business, although the effect for top students is not significant in 2013, it is almost double the effect found for average 
students in 2014, yielding an estimated increase of 0.85 points on average grades (on a 0 to 10 scale). In medicine, the value of the estimated impacts, when significant, are also higher for top students, averaging increases of around 0.6 points in 2013 and 0.4 in 2014 as compared to an approximate 0.2 increase for average students in 2012 and 2014. A plausible explanation for this performance on the part of top students may lie in the fact that, as mentioned above, the tuition fees system at UV awards total exemption from payment in one module in the incoming academic year for each module in which the student got a Distinction in the previous year. This incentive is not negligible since, according to the UV fee structure detailed in Table 1, students could save up to 80 euros for the first registration in a six-credit module in economics-business, and over 100 euros for an equivalent module in medicine. In our view, however, this does not invalidate our theoretical finding that average students will tend to make a greater effort in order to pass the exams at the first sitting. Rather, it reflects the fact that our model is not intended to capture this particular effect that can appear at the upper end of the distributions of grades and student ability.

Thus, our econometric results indicate that students have responded to the 2012 fee rise by taking each exam fewer times, increasing their probability of passing at the first attempt, and also improving their academic grades. Average students respond more clearly than their top classmates in terms of the first two indicators, while top students seem to be more driven than average ones to respond by improving their academic grades. The reason behind these larger changes in grades of top students could be the higher fee savings on offer after 2012 if a student gains a Distinction in a module.

In the next section we explore whether these results could be confounded by a possible sample composition effect after the 2012 fee rise, either in the form of positive self-selection of students through enrolment or because of a higher incidence of dropouts among less able students.

\subsection{Composition effects of enrolment and dropouts}

A possible concern regarding the identification of the causal effects of the tuition fee rise in 2012 stems from the possibility that the reform affected the likelihood of enrolment and dropout, depending on students' ability and/or academic performance. Rational economic decision-making would suggest that, when faced with higher tuition fees, students who are marginal in terms of ability or prior academic performance could be discouraged from enrolling at university because of the increased costs that have to be offset against the expected benefits. This would lead to higher ability, on average, of students coming to 
Table 8: Grades. Fully flexible DID regression.

\begin{tabular}{|c|c|c|c|c|c|c|}
\hline & \multicolumn{3}{|c|}{ ECONOMICS and BUSINESS } & \multicolumn{3}{|c|}{ MEDICINE } \\
\hline & All Stud. & Averg. Stud. & Top Stud. & All Stud. & Averg. Stud. & Top Stud. \\
\hline \multirow[t]{2}{*}{ Year 2011} & $0.343^{* * *}$ & $0.251^{* * *}$ & $0.610^{* *}$ & 0.057 & 0.096 & -0.114 \\
\hline & $(0.076)$ & $(0.096)$ & $(0.244)$ & $(0.069)$ & $(0.078)$ & $(0.173)$ \\
\hline \multirow[t]{2}{*}{ Year 2012} & $0.559^{* * *}$ & $0.608^{* * *}$ & $0.409^{* *}$ & -0.032 & -0.092 & 0.223 \\
\hline & $(0.084)$ & $(0.101)$ & $(0.194)$ & $(0.069)$ & $(0.074)$ & $(0.142)$ \\
\hline \multirow[t]{2}{*}{ Year 2013} & $0.874^{* * *}$ & $0.838^{* * *}$ & $1.097^{* * *}$ & $0.441^{* * *}$ & $0.559^{* * *}$ & 0.057 \\
\hline & $(0.081)$ & $(0.086)$ & $(0.172)$ & $(0.065)$ & $(0.072)$ & $(0.135)$ \\
\hline \multirow[t]{2}{*}{ Year 2014} & $0.810^{* * *}$ & $0.900^{* * *}$ & 0.383 & $0.664^{* * *}$ & $0.710^{* * *}$ & $0.458^{* * *}$ \\
\hline & $(0.081)$ & $(0.086)$ & $(0.265)$ & $(0.066)$ & $(0.076)$ & $(0.133)$ \\
\hline \multirow[t]{2}{*}{ Treated in Year 2011} & -0.062 & 0.043 & -0.376 & -0.039 & -0.065 & 0.082 \\
\hline & $(0.076)$ & $(0.095)$ & $(0.244)$ & $(0.067)$ & $(0.079)$ & $(0.170)$ \\
\hline \multirow[t]{2}{*}{ Treated in Year 2012} & 0.069 & 0.050 & 0.102 & $0.198^{* * *}$ & $0.231^{* * *}$ & 0.051 \\
\hline & $(0.084)$ & $(0.100)$ & $(0.193)$ & $(0.069)$ & $(0.073)$ & $(0.143)$ \\
\hline \multirow[t]{2}{*}{ Treated in Year 2013} & $0.201^{* *}$ & $0.256^{* * *}$ & -0.089 & $0.224^{* * *}$ & 0.117 & $0.572^{* * *}$ \\
\hline & $(0.080)$ & $(0.084)$ & $(0.175)$ & $(0.065)$ & $(0.073)$ & $(0.138)$ \\
\hline \multirow[t]{2}{*}{ Treated in Year 2014} & $0.494^{* * *}$ & $0.425^{* * *}$ & $0.842^{* * *}$ & $0.215^{* * *}$ & $0.179^{* *}$ & $0.383^{* * *}$ \\
\hline & $(0.080)$ & $(0.085)$ & $(0.264)$ & $(0.064)$ & $(0.074)$ & $(0.135)$ \\
\hline N Obs & 213296 & 170580 & 42716 & 76245 & 60908 & 15337 \\
\hline $\mathrm{R}^{2}$ & 0.459 & 0.441 & 0.507 & 0.569 & 0.562 & 0.562 \\
\hline
\end{tabular}

the university after the fee rise. As regards dropouts, higher tuition fees could make it more likely that less able students drop out, just to avoid incurring increasingly higher costs. These selection mechanisms could have resulted in changes to the composition of the UV student body. If that were the case, the reduction in the number of registrations required to pass, the increase in the probability of passing at the first attempt or the improvement in grades might not in fact be attributable to higher student effort but rather to a compositional change in the estimation sample resulting in a preponderance of high ability students from 2012 onwards. In this section we present evidence that rules out a composition effect as a confounding factor in the analysis.

First, to check if enrolment changed after 2012 resulting in a prevalence of high ability students, we estimate a flexible DID equation like equation (3) in which the dependent variable is the enrolment grades of the students entering either economics-business or medicine during the period under analysis. The underlying assumption in this estimation is that higher tuition fees might have had an effect on the enrolment decisions of fee-paying students. Hence, the DID approach in this case seeks to capture whether regular students entering the university from academic year 2012/13 onwards were, on average, more able students than their control counterparts entering the same year. Since in our sample 
entrants account for near 45 percent and 35 percent of the total number of students in economics-business and medicine, respectively, a change in the relative ability of treated versus control students entering after the fee rise could be of relevance in determining the observed differences in our main DID analysis above. Results in Table 9, however, allow us to rule out this concern. The estimation in this case only uses one observation per student (the grade on the student's university application), and it has been obtained by OLS. Control variables also included in Tables 6 to 8 are the student's age and gender, educational level of the father and mother and the rest of the proxies for the student's employment status and that of their parents. The estimated differences in entrance grades between treated and control students after 2012 not only do not show any clear sign, but are strongly statistically insignificant. We conclude that there is no evidence in our data of a composition effect due to enrolment driving our main econometric results presented above.

Second, we look into a possible composition effect due to dropouts. In this case, we follow a different empirical strategy, with estimation results presented in Table 10. In this table, we repeat the DID regressions of Tables 6 to 8 removing from the estimation sample all the observations coming from students who end up dropping out of the university, and check if the results hold. In our estimation sample, only around 5 and 3 percent of students in economics-business and medicine, respectively, drop out. The percentages of observations coming from these students are, then, very low. The effects, if any, are thus not expected to be noticeable. ${ }^{13}$ The evidence in Table 10 strongly supports the robustness of our main econometric results above since they remain virtually unchanged.

\section{Discussion}

The reform undertaken in the Spanish public university system following Law 14/2012 entailed an unprecedented hike in the cost per credit taken by students in higher education. In this study, we provide evidence that this tuition fee rise has very likely stimulated academic effort on the part of students. If this effect does in fact occur, then a measure that initially aimed at easing universities' budget constraints would have also brought about a gain in efficiency in the use of public educational resources. As we have found, this is the case when more effort is exerted to shorten time-to-graduation and to improve

\footnotetext{
${ }^{13}$ Notice that these figures do not refer to dropout rates as they are commonly understood, since they are not calculated over the cohort of students entering one year but over the total stock of students who are present over all the years in our sample. Recent official data on dropouts in the public universities in the region of Valencia report rates of around 20 percent in the academic year 2014/15, most of them occurring during the first year of the degree (Ministerio de Educacion, Cultura y Deporte, 2015).
} 
Table 9: Enrolment grades

\begin{tabular}{lcc}
\hline \hline & Economics-Business & Medicine \\
\hline Treated & -0.010 & 0.129 \\
Year 2011 & $-0.380)$ & $(0.470)$ \\
& $(0.667)$ & -0.812 \\
Year 2012 & $-1.616^{* * *}$ & $(0.647)$ \\
& $(0.436)$ & 0.129 \\
Year 2013 & $-1.761^{* * *}$ & $-0.678)$ \\
& $(0.503)$ & $(0.699)$ \\
Year 2014 & $1.655^{* * *}$ & $2.485^{* *}$ \\
& $(0.598)$ & $(0.994)$ \\
Treated in Year 2011 & -0.030 & 0.544 \\
& $(0.656)$ & $(0.528)$ \\
Treated in Year 2012 & 0.290 & -0.026 \\
& $(0.412)$ & $(0.536)$ \\
Treated in Year 2013 & 0.535 & 0.613 \\
& $(0.483)$ & $(0.564)$ \\
Treated in Year 2014 & -0.251 & -0.191 \\
& $(0.586)$ & $(0.947)$ \\
\hline N Obs (students) & 3032 & 751 \\
$\mathrm{R}^{2}$ & 0.544 & 0.832 \\
\hline Robust standard errors in parenthesis * $<<0.10 * *$ & $\mathrm{p}<0.05 * * *$ \\
$\mathrm{p}<0.01$ All regressions include as control variables: & age, gender, \\
educational level of father and & mother, employment status of \\
father and mother, student's employment status, & dummies for \\
type of studies of origin and a degree-specific dummy.
\end{tabular}

grades.

The size of our estimates is conditional on the specific population of students of economics-business and medicine at UV, something that should be kept in mind when extrapolating the results. The way in which the increase in tuition fees was applied varied notably between different Spanish universities, given that the law allows regional governments a great deal of flexibility in terms of how they implement it. For example, the average price increase per credit on first registration ranged from 0 percent in Galicia and Asturias to 67 percent in Catalonia, with Valencia somewhere in the middle. More interestingly, the structure of escalating tuition fees with the number of registrations was also quite different from region to region, with some choosing a small increment between the first two registrations and a large increase beyond the second one for subsequent reg- 


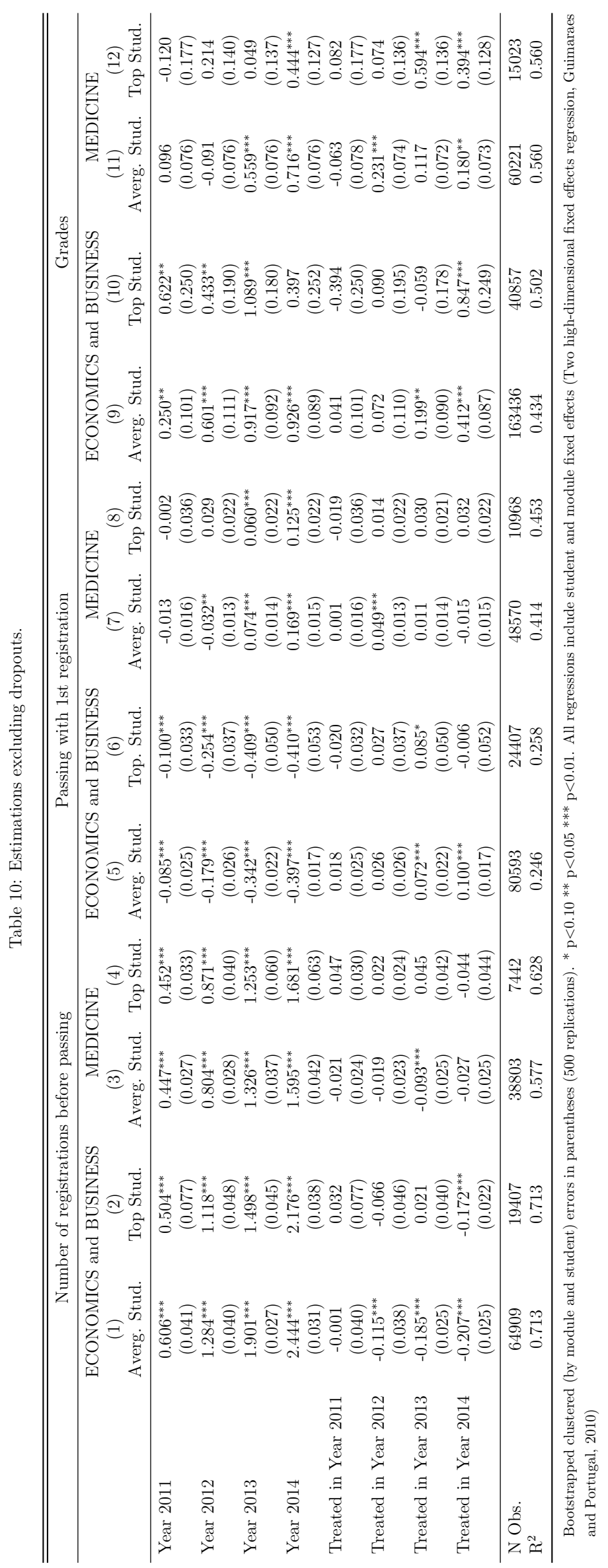


istrations (as in Catalonia), while others preferred to apply a higher increment the first and the second registration (as in Madrid). A relevant question that is worth exploring is the extent to which different designs in the tuition fee structure could affect the relevant outcomes for policy evaluation. The complete evaluation of a particular tuition fee structure should take into account at least three considerations: first, the impact on public revenues; second, its direct influence on students' utility; and third, the aforementioned effect on student effort, which translates into efficiency gains.

Higher tuition fees are expected to raise university revenues, unless they have a marked effect on enrolment and dropouts. ${ }^{14}$ The impact of the policy on students' utility very likely depends on personal attributes such as leisure preferences, fallback income or ability. A tuition fee rise of the size observed at UV may have penalised, for instance, students from low income families which are more likely to suffer from budgetary constraints. Regarding the effect on student effort, if the measure reduces the probability of late graduation, as our empirical analysis suggests, it may result in large savings in public resources (in terms, for instance, of teaching duties) as well as in a significant contribution of tax revenues due to students' earlier entry into the labour market. Also in efficiency terms, and to the extent that better grades reflect greater knowledge, the policy also results in positive external effects on the economy which go above and beyond the intended aim of the policy.

Is there any specific tuition fee structure that is preferable over another in terms of the three relevant outcomes for policy evaluation? Although in the empirical section we are able to identify the effect of the policy as a whole, we cannot separate the part of the effect stemming from the rise in fees for the first registration from the part that stems from the increase in the penalty for successive attempts. We can, however, use our simple theoretical model to shed some light on that question.

In Table 11 we simulate a university populated with two types of students with different levels of ability weighted according to our sample percentages of average and top students (80 and 20 percent, respectively). The rest of the parameters characterising these two types of students are identical in the two groups and the same as those we set in section 3. The upper part of the table displays the model solution for the pre-fee rise situation, both for average and top students, and then for the weighted average of these values in the last column. As outcomes for policy evaluation we focus on student effort $(s)$ and the probability of passing with the first registration $(F)$, as indicators of an efficiency effect; the student utility $(U)$, representing the direct welfare effect for enrolled students;

\footnotetext{
${ }^{14}$ Several studies encounter tuition elasticities in higher education of less than one (see Hemelt and Marcotte, 2011, for instance), suggesting increased revenues when tuition are increased.
} 
and the expected university revenues coming from tuition-fees $(R)$. As expected, average students have a lower probability of finishing the degree on time and display lower utility than their high ability peers.

Next, we simulate the effect of the 2012 fees-rise changing both the level of the tuition fees, $m$, and the step penalty, $d$, and calculate the resulting changes in the variables of interest. The expected amount of revenue collected by the university increases considerably, although it comes at the expense of direct students' utility. Effort and the probability of early completion increase more for low ability students, and the result is a more pronounced drop in their utility. We refer to this as a mixed design, which combines changes in $m$ and in $d$, and its results are taken as our benchmark in the remainder of the simulation exercise.

Next we analyse in Table 11 two designs for a rise in tuition fees: one corresponding to an increase in the penalty for successive registrations while maintaining the initial tuition cost constant (what we might call the $d$-biased or escalating design) and another that represents a rise in $m$ leaving $d$ constant (the $m$-biased or level design). For each of these two designs we perform two experiments. In the first, we increase the cost of enrolment up to the point where the average drop in utility for all the enrolled students is the same as in the benchmark experiment. In the second, we keep the increase in university revenues constant instead. Thus, the three designs can be considered as equivalent in terms of changes in students' utility ( $\Delta U$ constant in the table) or in terms of fees revenues $(\Delta R$ constant in the table).

Comparing the three designs of tuition fee rises, we can highlight three main results. First, no one design is clearly better than the others. After controlling for the welfare effect, the escalating design performs better than the benchmark design in terms of efficiency, but worse in terms of revenue collection. The opposite is true for the level design. Second, a level scheme would prove especially harmful for top students while it would benefit average students more than a mixed design or an escalating design would. Third, when keeping the change in university revenues constant, an escalating design that heavily penalises failing the exams at the first registration would provoke the highest positive effect on effort and time-to-completion at the expense of an important fall in direct utility for less able students. However, this design is also very likely to cause the smallest distortion on the decision to enrol, especially for low income/low ability students.

Our results have to be understood as only one additional piece of information contributing to the general debate about how a public university system should be financed. How the tuition fee rise affects the number of enrolments or how educational authorities handle with equity issues (using grants or fostering loans policies, for example) is also a matter 
Table 11: Theoretical effects of different tuition fees structures

\begin{tabular}{l|l|rrr}
\hline \hline \multicolumn{1}{l}{} & \multicolumn{1}{c}{ Average students } & Top students & All students \\
\hline \hline & $\mu$ & 7 & 5 & 6.6 \\
\hline \multirow{3}{*}{ Initial levels } & $s$ & 6.53 & 5.74 & 6.34 \\
& $F$ & 0.38 & 0.68 & 0.45 \\
& $U$ & 8.06 & 9.91 & 8.50 \\
& $R$ & & & 0.99 \\
\hline \hline & $\Delta s$ & 0.65 & 0.29 & 0.58 \\
Benchmark change in $m$ and $d$ & $\Delta F$ & 0.16 & 0.06 & 0.14 \\
& $\Delta U$ & -0.46 & -0.32 & $\mathbf{- 0 . 4 4}$ \\
& $\Delta R$ & & & $\mathbf{0 . 8 7}$ \\
\hline \hline & $\Delta s$ & 0.73 & 0.34 & 0.65 \\
Change in $d$ and $m$ constant & $\Delta F$ & 0.18 & 0.07 & 0.16 \\
$(\Delta U$ constant) & $\Delta U$ & -0.47 & -0.30 & $\mathbf{- 0 . 4 4}$ \\
& $\Delta R$ & & & 0.79 \\
\hline \multirow{2}{*}{ Change in $m$ and $d$ constant } & $\Delta s$ & 0.49 & 0.19 & 0.43 \\
$(\Delta U$ constant) & $\Delta F$ & 0.12 & 0.04 & 0.11 \\
& $\Delta U$ & -0.44 & -0.39 & $\mathbf{- 0 . 4 4}$ \\
& $\Delta R$ & & & 1.03 \\
\hline \hline
\end{tabular}

of concern that, although beyond the scope of our analysis, merits further attention.

\section{Conclusion}

In this paper, we have studied the potential effects of tuition fees on university students' academic effort. To this end, we have examined the particular tuition fee rise introduced by Law 14/2012 in Spanish public universities, whereby students register and pay for their chosen modules and fees increase each time students retake a module, until they pass it. Data refers to all students of economics, business and medicine at the University of Valencia, one of the largest public universities in Spain, during the period 2010-2014.

The fact that some students pay fees in full while others are totally exempt from payment provides an identifying source of variation in tuition that we have exploited to 
apply a flexible difference-in-differences methodology. After controlling for unobserved heterogeneity across students and also across modules we have found that, after academic year 2012/13 and as compared with exempt students, those paying fees have: i) reduced the average number of times they register for a single module before passing it; ii) increased the probability of passing with the first registration; and iii) improved their academic grades. The effects differ depending on the ability of the student, among university degrees and over the years after 2012. In particular, less able (or average) students in economics and business are those that exhibit the largest responses. As a point in case, compared to figures from before 2012, average students in economics and business have almost halved the number of times they retake a module and have increased the probability of passing with the first registration by around 10 percent, an increase that brings these students closer to their more able classmates in terms of this probability. The obvious consequence of these results is a reduction in degree completion time. In doing so, students have also improved their academic grades, in some cases by up to 0.8 points (out of 10) above the pre-2012 average values. Selection of better students after 2012, either through enrolment or dropouts, does not appear to be a concern in our data.

Although in the empirical section we are able to identify the effect of the policy as a whole, we cannot determine which part of the effect is due to the higher fees overall and which comes from the increasing penalty for successive attempts to pass exams. Is, for instance, an escalating tuition fee structure preferable to another that applies fees regardless of the number of times students sit exams? A final simulation exercise with our theoretical model suggests that the escalating design could be preferable in terms of use efficiency but less so in terms of fee revenues. A level scheme, however, could be especially harmful for top students while benefiting low ability students, when compared with an escalating fee structure or a combination structure, such as the Spanish system.

In brief, our results reveal interesting gains in terms of efficiency in the use of the educational resources in response to increased tuition fees, which we believe is a highly desirable target of the educational policy. Our paper also emphasises the importance of analysing the particular design of tuition fee structures in higher education. A more in-depth examination of this latter question remains, however, on the research agenda. 


\section{References}

Angrist, J., Lang, D., and Oreopoulos, P. (2009). "Incentives and services for college achievement: Evidence from a randomized trial", American Economic Journal: Applied Economics, 1(1), 136-163.

Angrist, J., and Lavy, V. (2009). "The effects of high stakes high school achievement awards: Evidence from a randomized trial," The American Economic Review, 99(4), 13841414 .

Ashworth, A., Dearden, L., Emmerson, C.,, Frayne Ch.,, Hardman, H., Hartfree, H., Maguire, S., Megir, C., Middleton, S., and Smith, D. (2002). Education Maintenance Allowance: the first two years: a quantitative evaluation (No. RR352). Department for Education and Skills.

Becker,G.S. (1965): "A theory of allocation of time," The Economic Journal, 299(75), 493-517.

Bolli, T. and G. Johnes (2015): "In my own time: tuition fees, class time and student e§ort in non-formal (or continuing) education," Journal of Education and Work, 28(6), 592-606.

Bradley, S. and Migali, G. (2015). "The Effect of a Tuition Fee Reform on the Risk of Drop Out from University in the UK," Working Paper. 2015/016 Lancaster University, Department of Economics.

Camerer, C. F., and Hogarth, R. M. (1999). "The effects of financial incentives in experiments: A review and capital-labor-production framework," Journal of risk and uncertainty, 19(1-3), 7-42.

Deming, D., and Dynarski, S. (2009). Into college, out of poverty? Policies to increase the postsecondary attainment of the poor, National Bureau of Economic Research WP. 15387.

Dynarski, S. (2008). "Building the stock of college-educated labor," Journal of human resources, 43(3), 576-610.

Garibaldi, P., Giavazzi, A., Ichino, A. and Rettore, E. (2012). "College cost and time to complete a degree: evidence from tuition discontinuities," The Review of Economics and Statistics, vol. 94(3), 699-711.

Groen, J. A., Jakubson, G. H., Ehrenberg, R. G., Condie, S., and Liu, A. Y. (2008). "Program design and student outcomes in graduate education," Economics of Education Review, 27(2), 111-124.

Greenaway, D., and Haynes, M. (2003). "Funding higher education in the UK: The 
role of fees and loans," The Economic Journal, 113(485), 150-166.

Guimaraes, P., and Portugal, P. (2010). "A simple feasible alternative procedure to estimate models with high-dimensional fixed effects," Stata Journal, vol. 10(4), 628-649.

Heineck, M., Kifmann, M., and Lorenz, N. (2006). "A duration analysis of the effects of tuition fees for long term students in Germany," University of Konstanz, Centre for European Economic Research discussion paper n $\int 5$.

Hemelt, S. W., and Marcotte, D. E. (2011). "The impact of tuition increases on enrollment at public colleges and universities," Educational Evaluation and Policy Analysis, $33(4), 435-457$.

Hübner, M. (2012). "Do tuition fees affect enrollment behavior?," Evidence from a natural experiment in Germany. Economics of Education Review, 31(6), 949-960.

Hutchins, S.S., Brown, C., Mayberry, R., and Sollecito, W. (2015). "Value of a small control group for estimating intervention effectiveness: results from simulations of immunization effectiveness studies," Journal of Comparative Effectiveness Research, 4(3), 227-238.

Ketel, N., Linde, J., Oosterbeek, H., and Klaauw, B. (2016). "Tuition Fees and SunkCost Effects," The Economic Journal, .

Kremer, M., Miguel, E., and Thornton, R. (2009). "Incentives to learn," The Review of Economics and Statistics, 91(3), 437-456.

Leuven, E., Oosterbeek, H., and Klaauw, B. (2010). "The effect of financial rewards on students' achievement: evidence from a randomized experiment," Journal of the European Economic Association, 8(6), 1243-1265.

Lochner, L. J., and A. Monge-Naranjo (2011). "The nature of credit constraints and human capital," American Economic Review, 101, 2487-2529.

Ministerio de Educación, Cultura y Deporte. (2015). "Datos y cifras del sistema universitario español, Curso 2014/15". (mecd.gob.es)

Mora, R., and Reggio, I. (2012). "Treatment effect identification using alternative parallel assumptions," Working Paper 12-33, Economic Series (48), Department of Economics, University Carlos III, Madrid.

Pérez, F., Pastor, J.M., and Peraita, C. (2015). El impacto socioeconómico de las universidades públicas valencianas. Tercer informe del SUPV. Instituto Valenciano de Investigaciones Económicas (IVIE).

Sá, F. (2014). The Effect of Tuition Fees on University Applications and Attendance: Evidence from the UK. IZA Discussion Paper No. 8364

Sacristán, V. (2014). El coste de estudiar en Europa. Precios, becas, préstamos y otras ayudas en las universidades europeas (2013-2014). Colaboraciones: Alfonso Herranz y 
Jordi Mir. Ed. Oriol Arcas. 


\section{Appendix}

\section{Model parameterisation.}

In order to provide values for the parameters we start by normalising total time and present value secure income and set $h=y_{0}=10$. Now, to obtain a value for $m$ we need to relate the empirical cost of tuition fees and the model value for $y_{0}$. First, we assume that the annual real income of a non-graduate worker with secondary education will be $y^{a}=12,000$ euros a year (1,000 euros a month), and that will remain constant over the worker's lifetime. We consider an FC certificate to be the type that is awarded when courses are passed with the first registration. From the information on the actual cost of tuition fees at UV during the courses 2010/11 and 2011/12, we obtain the annual pretreatment fees cost of an FC certificate $\left(m_{F C}^{a}\right)$ during the courses 2010/11 and 2011/12.

We can calculate the observed annual tuition cost of being enrolled at university relative to income and conditional on obtaining an FC certificate as $\kappa=\frac{m_{F C}^{a}}{y^{a}}$. We define $n_{u}$ as the average number of years a Spanish student actually needs to complete their university degree. Let $n_{w}$ represent the average period during which a student completing secondary education and entering the labour market will receive income. For a subjective discount rate, $\gamma$, the annual model income corresponding to the present value lifetime income $y_{0}$ is:

$$
y_{0}^{a}=\left[\frac{1}{1-\gamma}-\frac{\gamma^{n_{w}}}{1-\gamma}\right]^{-1} y_{0}
$$

which allows us to obtain the value for the model tuition fees as

$$
m=\kappa y_{0}^{a}\left[\frac{1}{1-\gamma}-\frac{\gamma^{n_{u}}}{1-\gamma}\right]
$$

We set $n_{u}=4$ and $n_{w}=60$. Further we set $\gamma=0.8$ under the assumption that young students are usually impatient and, when facing decisions about time and effort, they discount the future quite heavily.

We use the value of $m$ and additional information about tuition fees for third and fourth registrations to assign the value for the pre-treatment tuition fees penalty $d$. Parameter $\beta$ is set under the assumption that when the student gets a degree with an SC certificate (meaning more than two registrations), they obtain a reward of $15 \%$ with respect to $y_{0}$. On the other hand, we assume that getting an FC certificate doubles the income with respect to a worker with just secondary education, and then fix $b=y_{0}$. As having an FC certificate signals not only effort capacity but also a higher level of skills positively related to an individual's productivity, we assume that $b$ is typically higher than $s^{\beta}$. We set a 
value of $\mu=6.6$, so we consider the probability function for a representative student close to the dashed line in Figure 1. Finally, we set $\alpha$ such that, conditional on the values of the rest of parameters, $F(\mu, s)$ replicates the probability of passing with the first registration for economics and business at the University of Valencia. 